\title{
Research and analysis of residual stress measurement of ram casting in gantry machine center Rong WANG ${ }^{1}$, Xinmeng SUI ${ }^{2, a}$, Deqiang WEI
}

${ }^{1}$ School of mechanical and electrical engineering guilin university, Guangxi 541004, China;

${ }^{2}$ School of mechanical and electrical engineering guilin university, Guangxi 541004, China. a799456725@qq.com

Keywords: ram casting, blind-hole method, esidual stress.

\begin{abstract}
Ram is one of the key component of high-end CNC machine tools, which casting residua 1 stress will affect its machining accuracy, quality and performance of machine seriously. This paper utilizing blind hole method to measure residual stress of ram cast-ing,the results show that: the scre $\mathrm{w}$ mounting face of ram castings is primarily compressive stress, the headstock mounting surface is mainly tensile stress, which tensile and compressive stresses coexist in other test surface. It can co ncluded that the headstock mounting surface residual stress is thet main reason for bending ram pr oduce. The residual stress of screw mounting surface and spindle box installation site is the main rea son for bending of ram. The spindle bearing installation position of Ram is the stress concentration a rea and the maximum stress value reached 193.2MPa, which is produce deformation or cracking eas ily. Through obtain the residual stress and its distribution can provide a reference for the design an $\mathrm{d}$ optimization of the ram structure by testing and analysis.
\end{abstract}

\section{Introduction}

With the rapid development of high-end manufacturing and equipment industry in our country, parts machining accuracy is becoming more and more demanding ${ }^{[1]}$. Ram is the core component of gantry machining center and an important factor affecting the quality of machining. The guide of ram casting is longer with big wall thickness. Because of uneven temperature distribution in the casting process, with the temperature drop, it can cause shrinkage and phase change, make internal stress in it[3]. When the internal stress was not eliminated completely will produced residual stress in the casting, residual stress will cause deformation of cracking formation of castings etc. It will affect the mechanical properties and service life of casting[4].This paper based on the ram casting of gantry machining center as the research object, using the blind hole method carries on the casting residual stress test and analysis.Finally, get the casting residual stress distribution and provide reference for the casting process.

\section{Residual stress test method}

\section{Test equipment and working principle of residual stress.}

The key to test residual stress use blind hole method is centering and punching. And the existing punching device is using microscope to centering, then use hand electric drill to drill. But this method has low accuracy, such as prone to vibration and Angle deflection, destroy hole roundness, affect the measurement results.

In order to improve the precision of punching, this paper design a high precision punching device, its specific structure as shown in figure 1, the device consists of two parts, centering and punching, the centering part by adsorption magnets, adjusting sleeve, dial indicator, cardiovascular , microscope and a center drill.

The working principle of the device as follows, cutting head adsorption with magnets, magnets adsorption by adjusting the dial indicator bracket connections, adsorption magnets and adjust the Angle of support the movement of the dial indicator is convenient for adjustment and centering 
calibration. Central microscope coat sleeve with microscope, microscope sleeve setting of the position of the lower part of the outer wall has a rectangular light mouth, convenient open lamp observation centering. Microscope set in the lower end of the sleeve has a powerful magnet fixed position, make the placement of microscope is more stable on the casting parts to be tested. The external cylindrical of Microscope socket was finishing by grinding machine, outside using microscope cylindrical sleeve with the microscope in the hole of the coaxial degree good, which can ensure the right microscope cross center and the microscope axis sleeve cylindrical overlap, complete accurate centering function.

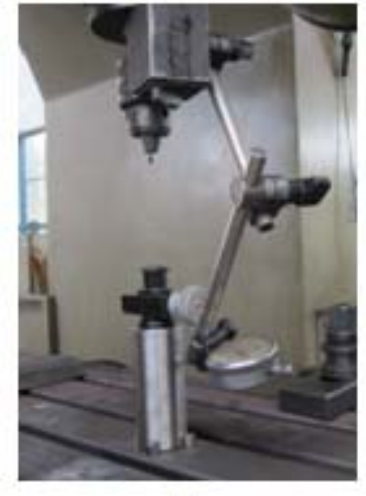

(a)

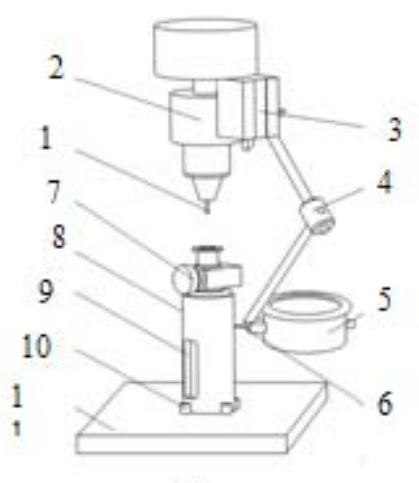

(b)

Fig.1 Centering drill equipment of residual stress testing

(a)Physical map of centering drill equipment in residual stress testing

(b)structure drawing of centering drill equipment in residual stress testing

1 - center drill 2-head of cutting tool 3-adsorption magnet 4-regulating bracket

5-Dial indicator 6-measuring head of dial indicator 7-central microscope

8-quill of microscope 9-light pass 10-powerful magnet 11-workpiece

\section{Residual stress test location.}

The ram casting material is HT300 and rectangle box structure, which size is: $2600 \mathrm{~mm} * 700 \mathrm{~mm}$ * $700 \mathrm{~mm}$, under the actual working condition, the ram before and after the two sides respectively equipped with spindle box and guide screw, the rest of the installation of auxiliary components. For the ram casting, casting internal cross even decorate stiffener, middle and outer wall has three Windows, according to the function of ram in the practical work, the surface mounting surface, before the end of the axle box, respectively guide screw and ram on the side. For the ram casting section, the structure to the asymmetric structure, uneven distribution of materials, local wall thickness is not consistent. Ram based on the actual conditions of deformation and structural characteristics, selection of spindle box installation, guide screw surface, the ram before end and side as a test.

Consider the structure characteristics of ram, place the test point respectively larger changes in the geometry size, reinforcement, guide rail surface and side, near the center of the spindle end and ram structure high stress concentration and deformation may occur, such as poor location conditions. The rest of the points according to the requirements or to have the combination of point data validation. The location of the specific test points as shown in figure 2 .

\section{Testing Steps of residual stress.}

According to CB3395-92 "test method for residual stress: the act of borehole strain release request, casting first test points with fine sand paper burnish, polishing, and then with acetone is swabbed clean, CG will be BX120-1 strain rosette (120 $\Omega$ resistance, the sensitive coefficient 2.0) with 502 glue paste in measured; Strain rosette on the wires to strain measuring instrument of zero. Using self-designed punching device in the center of the strain rosette drill a diameter of $1.5 \mathrm{~mm}$, deepth 2 $\mathrm{mm}$ holes, make the casting residual stress release. Using three 24 channels DH3818 static resistance strain gauge measurement, and each strain gauge with different temperature compensator (model BX120-3 a) to compensate. Testing process to ensure that the strain gauge, wires, strain gauge, etc will not be touched and jitter, test environment is dry, the temperature changes little point test process. Actual test as shown in figure 3 and 4.Ruled out for the heat generated by the drilling on the results, the influence of test test channel all the strain gauge balance when reset (drilling) after operation, no 
changes to strain gauge strain numerical when (the test strain release time is 120 minutes), the holes of the strain release completely and record each channel data by measurement.

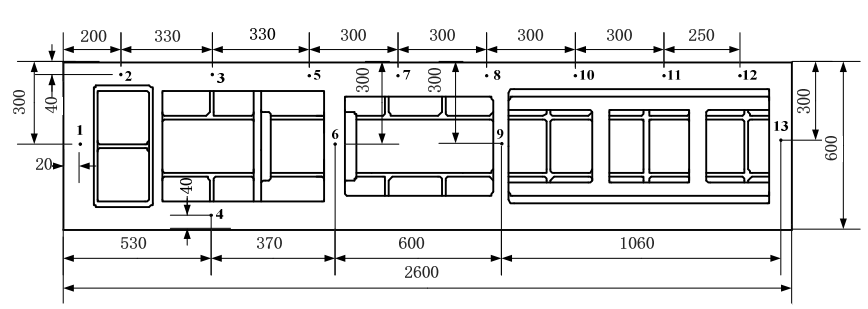

(a) Spindle box mounting surface

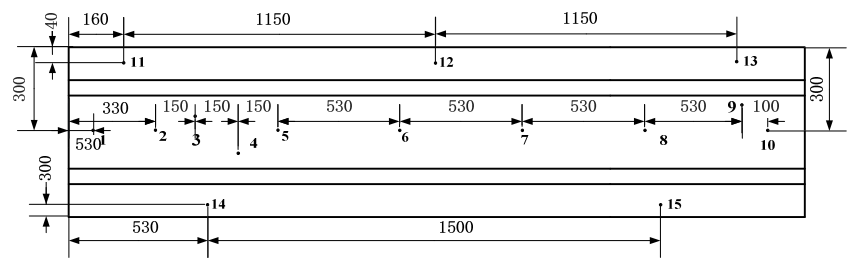

(c) surface of guide way and screw

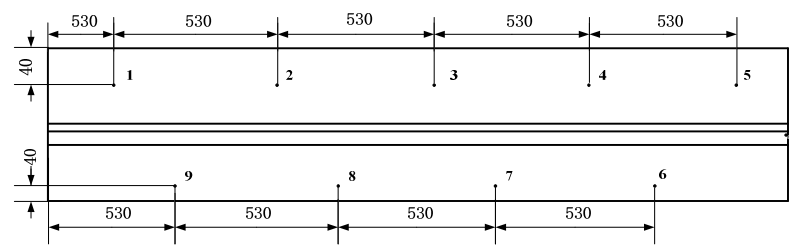

(d) surface of ram sid

Fig. 2 Testing positon of residual stress on ram casting
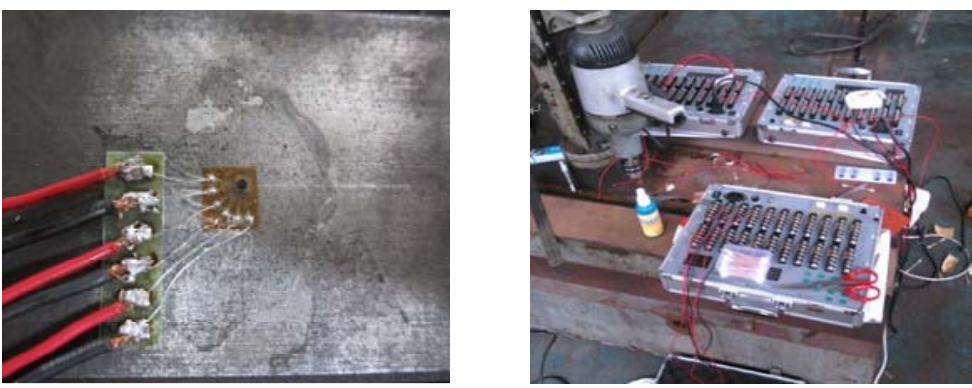

Fig.3 Adhesion of strain gauge

Fig.4 Residual stress testing site

\section{The results and analysis}

The measured residual strain by formula (1), (2) to calculate the residual stress:

$\sigma_{1,2}=\frac{\xi_{1}+\xi_{3}}{4 A} \pm \frac{1}{4 B} \sqrt{\left(\xi_{1}-\xi_{2}\right)^{2}+\left[2 \xi_{3}-\left(\xi_{1}+\xi_{2}\right)\right]^{2}}$

$\tan 2 \theta=\frac{2 \xi_{3}-\xi_{1}-\xi_{2}}{\xi_{2}-\xi_{1}}$

$\xi_{1} 、 \xi_{2} 、 \xi_{3}$--- Strain gauge at $0^{\circ}, 45^{\circ}, 90^{\circ}$ position measured by the release of strain;

$\sigma_{1} 、 \sigma_{2}$--- Residual stress in maximum and minimum principal stress (Mpa );

$\theta: \sigma_{1}$ and $\xi_{1}$ direction of Angle $\left(^{\circ}\right)$, clockwise orientation.If $\xi_{3} \geq \xi_{1}, \theta=\theta, \quad \xi_{3}<\xi_{1}, \quad \theta=\theta+90^{\circ}$;

A、B: Release coefficient, $\mathrm{A}=-0.037, \mathrm{~B}=-0.0598[16]$ 。

Calculated by the above method, maximum and minimum principal stress $\sigma_{1} 、 \sigma_{2}$, because of $\sigma_{2}$ compared with ${ }^{\sigma_{1}}$ relatively small, little change, do not discuss here. 


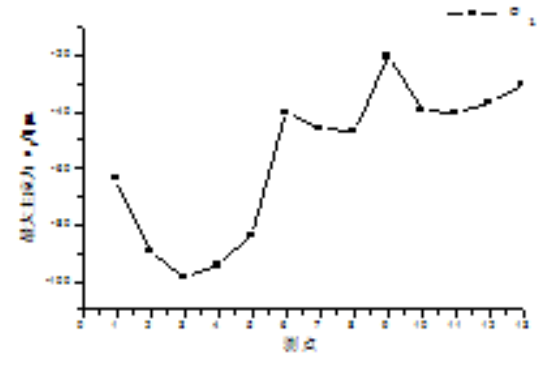

(a) Spindle box mounting surface

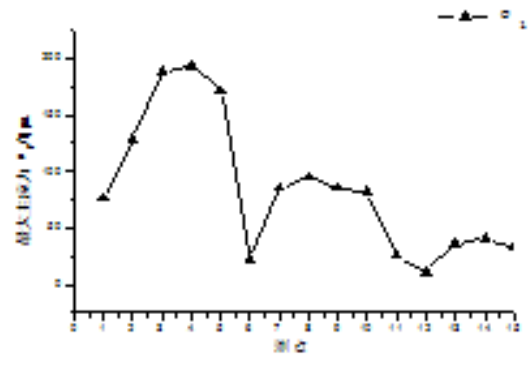

(c) surface of guide way and screw

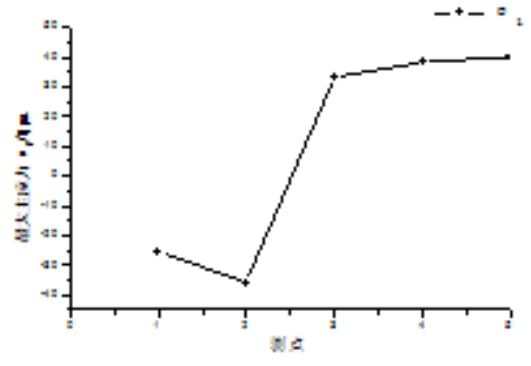

(b) front end surface

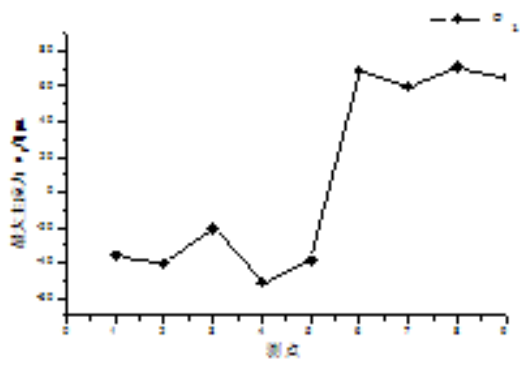

(d) surface of ram side

Fig. 5 the distribution of max main stress

\section{Summary}

1.This paper use blind hole method to measure the residual stress of ram casting, which residual stress is mainly compressive stress on the surface of the screw, main stress is tensile stress on the surface of the spindle box installation, the rest surface of the test have tensile and compressive stress at the same time.

2.The guide screw installed on the left side of the surface residual stress in large area, the maximum compressive stress value is $98.23 \mathrm{MPa}$. Ram front-end uniform surface has tension and compression stress distribution, maximum compressive stress is $35.95 \mathrm{MPa}$ and maximum tensile stress is $39.54 \mathrm{MPa}$; Guide screw on the maximum stress occurs in the spindle box installation site, the stress value of 193.2 MPa, close to the tensile strength of material HT300, which ram deformation or cracking was caused by the position; Side near the guide screw face a relatively large residual stress and maximum compressive stress is $50.8 \mathrm{MPa}$, the maximum tensile stress is $70.9 \mathrm{MPa}$.

3.According to analysis the test data, which can get that the spindle box and the guide screw surface residual stress distribution is a major cause of ram to generate bending deformation.

4.The material of ram casting distribution uneven, and the larger wall thickness difference and obvious structure mutation, easy to cause in the process of casting filling, solidification and cooling speed is differ, resulting in a large residual stress.

\section{Acknowledgements}

This work was financially supported by Guilin scientific research and technological development project (20140101-7).

\section{References}

[1] Schajer,G.S., Relaxation methods for measuring residual stresses, techniques and opportunities.[J]Experimental Mechanics, 2010, 50(8): 1117-1127

[2]Li Chen, Lou Ruixiang, Wang Zhigang, et al. Research Progress of measuring residual stress techniques[J] Materials Review, 2014, 11 (28) : 153-158 
[3] Dong Da-shan, Yu Xiang-dong. Residual stress measurement based on energy method [J]. Chinese Journal of Mechanical Engineering, 2014, 38 (12) : 92-96

[4] D. Akbari,I. Sattari-Far. Effect of the welding heat input on residual stresses in butt-welds of dissimilar pipe joints[J]. International Journal of Pressure Vessels and Piping . 2009,86 (11):769-776 